\title{
NTH201, a Novel Class II KNOTTED1-Like Protein, Facilitates the Cell-to-Cell Movement of Tobacco mosaic virus in Tobacco
}

\author{
Atsushi Yoshii, Takumi Shimizu, Akiko Yoshida, Koji Hamada, Keitaro Sakurai, Yasuyuki Yamaji, \\ Masashi Suzuki, Shigetou Namba, and Tadaaki Hibi \\ Laboratory of Plant Pathology, Graduate School of Agricultural and Life Sciences, The University of Tokyo, Yayoi 1-1-1, \\ Bunkyo-ku, Tokyo 113-8657, Japan
}

Submitted 15 October 2007. Accepted 10 January 2008.

\begin{abstract}
NTH201, a novel class II KNOTTED1-like protein gene, was cloned from tobacco (Nicotiana tabacum cv. Xanthi) and its role in Tobacco mosaic virus (TMV) infection was analyzed. Virus-induced gene silencing of NTH201 caused a delay in viral RNA accumulation as well as virus spread in infected tobacco plants. Overexpression of the gene in a transgenic tobacco plant ( $N$. tabacum cv. Xanthi nc) infected by TMV showed larger local lesions than those of the nontransgenic plant. NTH201 exhibited no intercellular trafficking ability but did exhibit colocalization with movement protein (MP) at the plasmodesmata. When NTH201-overexpressing tobacco BY-2 cultured cells were infected with TMV, the accumulation of MP but not of viral genomic and subgenomic RNA clearly was accelerated compared with those in nontransgenic cells at an early infection period. The formation of virus replication complexes (VRC) also was accelerated in these transgenic cells. Conversely, NTH201-silenced cells showed less MP accumulations and fewer VRC formations than did nontransgenic cells. These results suggested that NTH201 might indirectly facilitate MP accumulation and VRC formation in TMV-infected cells, leading to rapid viral cell-to-cell movement in plants at an early infection stage.
\end{abstract}

Additional keywords: KNOX, transcription factor.

To establish a systemic infection, plant viruses move first from cell to cell via plasmodesmata (PD), channels in the cell wall that provide symplastic continuity between adjacent plant cells. Cell-to-cell movement requires virus-encoded movement proteins (MPs) and several kinds of host plant proteins. It has

Corresponding author: T. Hibi; Telephone: +81-42-739-8247; Fax: +8142-739-8247; E-mail: akihibi@deluxe.ocn.ne.jp

Current address of A. Yoshii: Central Research Laboratories, Hokko Chemical Industry Co. LTD., 2165 Toda, Atsugi, Kanagawa 243-0023, Japan.

Current address of T. Shimizu: Research Team for Vector-Borne Disease, National Agricultural Research Center, Kannondai 3-1-1, Tsukuba, Ibaraki 305-8666, Japan.

Current address of T. Hibi: Research Institute, Tamagawa University, Tamagawa-gakuen 6-1-1, Machida, Tokyo 194-8610, Japan.

Nucleotide and amino acid sequence data reported are available in the DDBJ/EMBL/GenBank databases under accession number AB333840.

* The $e$-Xtra logo stands for "electronic extra" and indicates that two supplemental figures are published online. been reported previously that viral MPs are essential in cell-tocell movement, which themselves are able to move between cells, localize to PD, and increase the size-exclusion limit (SEL) (Boevink and Oparka 2005; Lucas 2006).

One of the most studied MPs is the $30-\mathrm{kDa}$ protein of Tobacco mosaic virus (TMV). The 6.3-kb RNA genome of TMV encodes an RNA-dependent RNA polymerase (RdRp) (126 and $183 \mathrm{kDa}$ ), a $30-\mathrm{kDa}$ MP, and a $17.5-\mathrm{kDa}$ coat protein (CP). TMV MP can bind viral single-stranded RNA to form a viral ribonucleoprotein (vRNP) complex to deliver its own genome to neighboring cells (Citovsky et al. 1990, 1992). Although TMV CP is not necessary for cell-to-cell movement (Saito et al. 1989, 1990), RdRp has an important role in vRNP movement (Hirashima and Watanabe 2001, 2003; Tamai and Meshi 2001). Recent studies have indicated that virus replication complexes (VRC), which include viral RNA, MP, RdRp, and some host proteins, are formed on the endoplasmic reticulum (ER) and might move to the adjacent cells (Asurmendi et al. 2004; Kawakami et al. 2004). It is important to identify which cellular factors interact with MP and to determine their functions in cell-to-cell movement. TMV MP has been reported to interact with cell-wall-associated pectin methylesterase (Chen and Citovsky 2003; Chen et al. 2000; Dorokhov et al. 1999) and calreticulin (Chen et al. 2005) as well as cytoskeletal elements such as F-actin (McLean et al. 1995), microtubules (Ashby et al. 2006; Heinlein et al. 1995; McLean et al. 1995), and microtubule-associated protein MPB2C (Kragler et al. 2003; Winter et al. 2007). Also, non-cell autonomous pathway protein 1 (NCAPP1) and PD-associated protein kinase (PAPK) that interacts with non-cell autonomous proteins (NCAP) were shown to affect TMV cell-to-cell movement (Lee et al. 2003, 2005). However, in vivo functions of these host factors in virus movement are not well understood.

As with viral MPs, some plant-encoded transcription factors are known to be able to traffic between cells and serve as signals to determine cell fate through cell-to-cell communication (Gallagher and Benfey 2005). Maize KN1 was the first characterized endogenous plant MP among KNOTTED1-like homeobox (KNOX) proteins (Lucas et al. 1995). KNOX proteins are divided into two classes depending on the homeobox (HOX) sequence (Bharathan et al. 1999; Deshpande et al. 1999; Hake et al. 2004; Kerstetter et al. 1994; Reiser et al. 2000). KN1, a class I KNOX protein, can increase the SEL and traffic itself and its own mRNA between cells, and normally is expressed in the shoot apical meristem (SAM), where it function in meristem development and maintenance (Kim et al. 2002, 2003; Lucas et al. 1995). Also, the other class I KNOX proteins, Arabidopsis 
KNAT1 and STM, and tomato LeT6 proteins that are closely related to KN1, can pass between cells (Kim et al. 2003, 2005). However, Arabidopsis KNAT2 and KNAT6, which are class I $\mathrm{KNOX}$ proteins but less closely related to KN1, have no trafficking ability (Kim et al. 2005).

On the other hand, class II KNOX proteins are expressed universally in most tissues but have no trafficking ability (Janssen et al. 1998; Kerstetter et al. 1994; Kim et al. 2005). However, the authentic functions of class II KNOX proteins in the plant cell are not clearly understood thus far.

Here, we show that NTH201, a novel class II KNOX protein of tobacco plant, positively controls the cell-to-cell move- ment of TMV by regulating the accumulation of MP and the formation of VRC, although it has no trafficking ability of its own.

\section{RESULTS}

Isolation of NTH201, a novel class II KNOX gene of tobacco.

To isolate a KNOTTED1-like HOX gene, a fragment of KNOX cDNA was amplified from Nicotiana tabacum total RNA by reverse transcription with a primer set based on the conserved sequences of three class II KNOX genes followed by polymerase chain reaction (PCR). We cloned a full-length

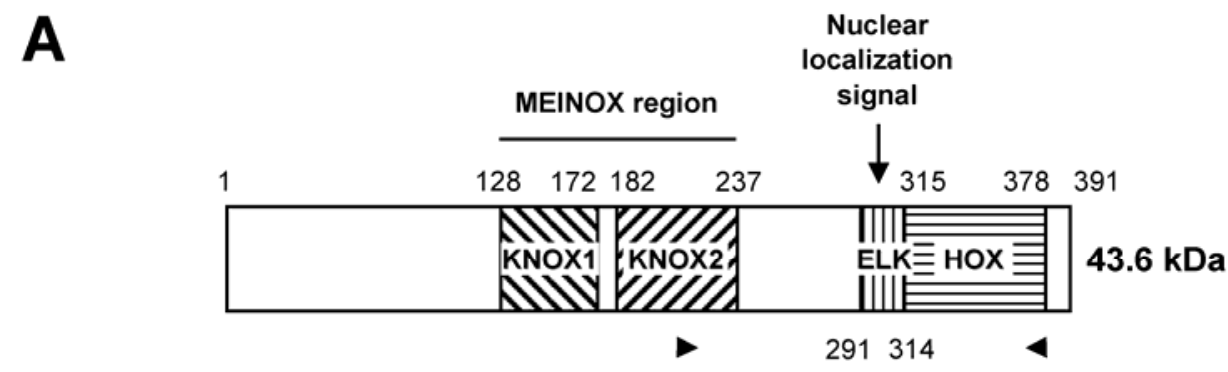

B
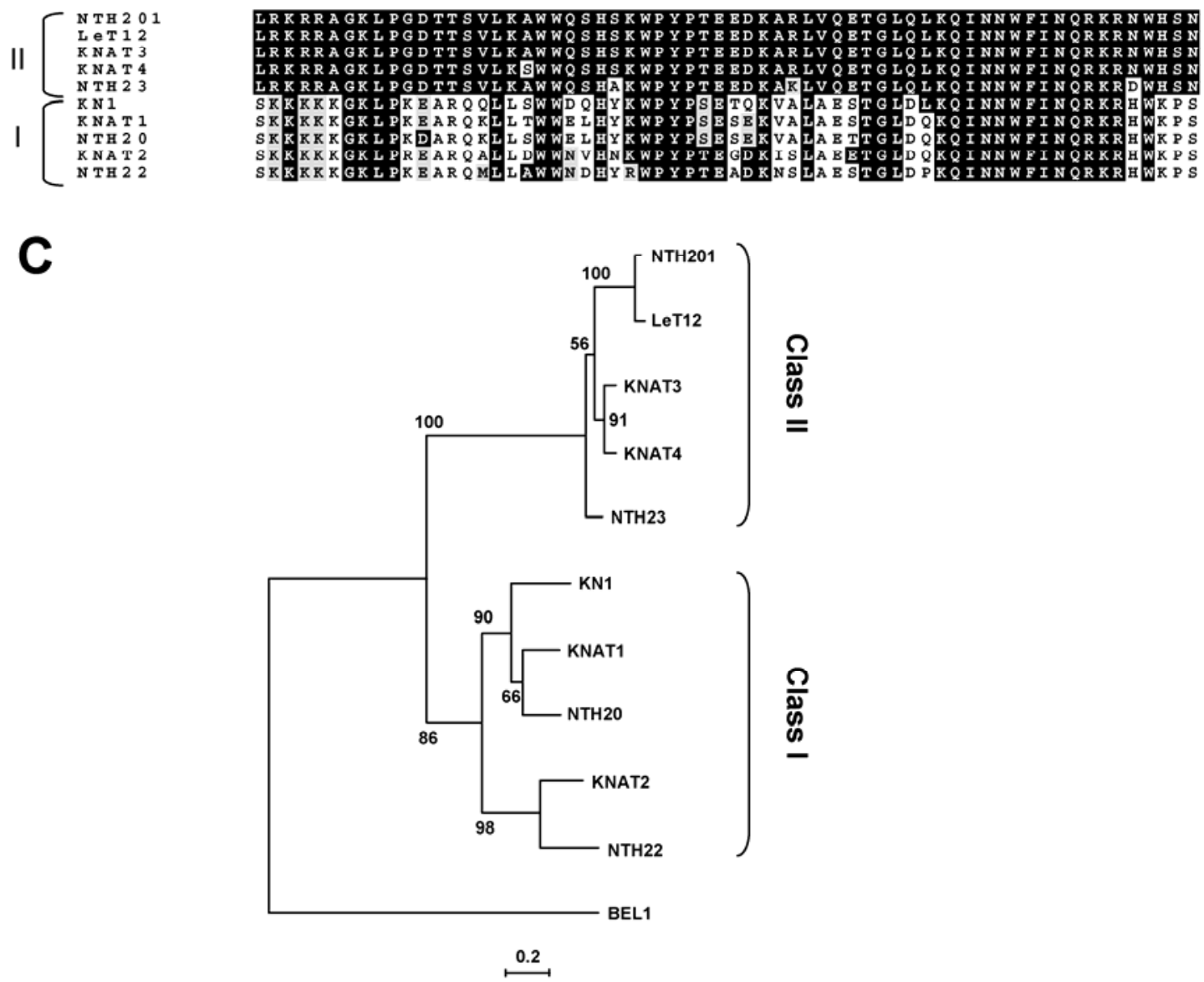

Fig. 1. Distinction of NTH201 as a novel class II KNOTTED1-like homeobox (KNOX) protein of tobacco. A, Deduced structure of NTH201 protein. The conserved domains of KNOX proteins (i.e., KNOX1, KNOX2, ELK, and homeobox [HOX]) are indicated with the amino acid numbers. Arrowheads are the corresponding positions of a set of polymerase chain reaction (PCR) primers. B, Amino acid sequences of HOX domains in several KNOX proteins. The HOX domains of tobacco NTH201 (this study; AB333840), NTH20 (AB025714), NTH22 (AB025715), and NTH23 (AB004797); Arabidopsis KNAT1 (U14174), KNAT2 (U14175), KNAT3 (X92392), and KNAT4 (X92393); tomato LeT12 (AF000142); and maize KN1 (Knotted1; X61308) are aligned using the CLUSTALW (version 1.83) and edited using BOXSHADE 3.21. Amino acids conserved among four or more of the proteins are highlighted in boldface, and similar residues are in gray. I = class I KNOX proteins and II = class II KNOX proteins. C, Phylogenic tree of the same KNOX proteins as those in B based on their total amino acid sequences. Arabidopsis BEL1 (U39944), a member of another homeodomain protein group, also was added for comparison. Numbers on branches indicate bootstrap values (1,000 repetitions) compatible with the 50\% majority rule. Only values $>50 \%$ are shown. CLUSTALW and NJPlot programs were used to generate the neighbor-joining tree. 
class II KNOX cDNA with a size of 1,551 bp by $5^{\prime}$ - and $3^{\prime}$ rapid amplification of cDNA ends (RACE) methods with genespecific primers. Sequence analysis of the full-length cDNA revealed 1,176 bp of open reading frame (ORF) encoding 391 amino acids with a predicted molecular weight of $43.6 \mathrm{kDa}$, designated as NTH201 (N. tabacum HOX protein 201; DDBJ accession number AB333840) following the previous naming convention of tobacco KNOX proteins (Sentoku et al. 1998). NTH201 belongs typically to the KNOX family proteins, with an N-terminal MEINOX region including the KNOX1 and KNOX2 domain, an ELK domain, and a highly conserved Cterminal HOX domain (Fig. 1A) (Bharathan et al. 1999; Kerstetter et al. 1994). Comparison of the HOX domain amino acid sequence of NTH201 with those of class I KNOX proteins (tobacco NTH20 and NTH22, Arabidopsis KNAT1 and KNAT2, and maize KN1) and class II KNOX proteins (tobacco NTH23, tomato LeT12, and Arabidopsis KNAT3 and KNAT4) revealed that NTH201 is highly homologous to class II KNOX proteins (Fig. 1B). This also was supported by the phylogenic analysis of the same KNOX proteins based on their total amino acid sequences (Fig. 1C). The total amino acid sequence homology between NTH201 and NTH23 was 65\%, which indicates that NTH201 is a novel class II KNOX protein of tobacco.
Silencing of NTH201 impaired TMV infection.

First, to examine whether NTH201 is involved in TMV infection, the endogenous NTH2O1 gene was silenced using the virus-induced gene silencing (VIGS) method (Burton et al. 2000; Ruiz et al. 1998). A partial sequence in the $3^{\prime}$-untranslated region (UTR) of the $N T H 2 O 1$ gene was cloned into a Potato virus $X$ (PVX) cDNA vector to construct pPVXNTH201, while the empty vector (pPVX) was used as a negative control. Approximately 3 weeks after bombarding of pPVX-NTH201 or pPVX vectors into young $N$. benthamiana leaves, the upper leaves showing very mild symptoms by the vectors were secondarily inoculated with TMV-green florescent protein (GFP) that is capable of expressing GFP together with RdRp, MP, and heterologous CP (Shivprasad et al. 1999). Approximately 1 week after the second inoculation, the inoculated leaves were visualized under UV irradiation to detect GFP-expressing infection foci formed by the virus spread.

Results of silencing experiments are shown in Figure 2. Silencing led to approximately 50\% reduction of $\mathrm{NTH} 201$ mRNA in NTH201-silenced plants compared with the control plants infected with pPVX vector alone, as indicated by realtime reverse-transcription (RT)-PCR analysis (Fig. 2A). These NTH201-silenced plants showed no major morphological differences from the control pPVX-infected plant. In contrast to
A

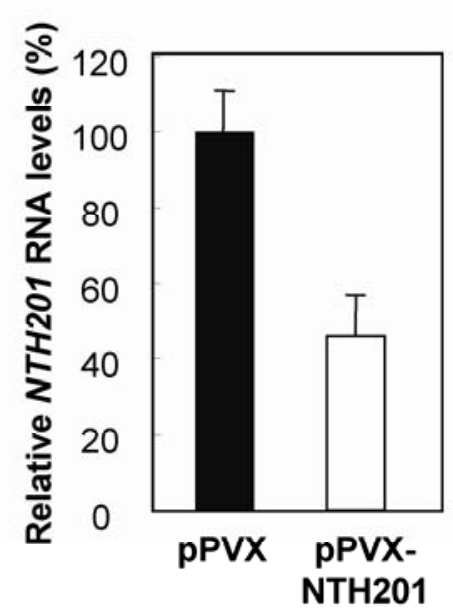

C

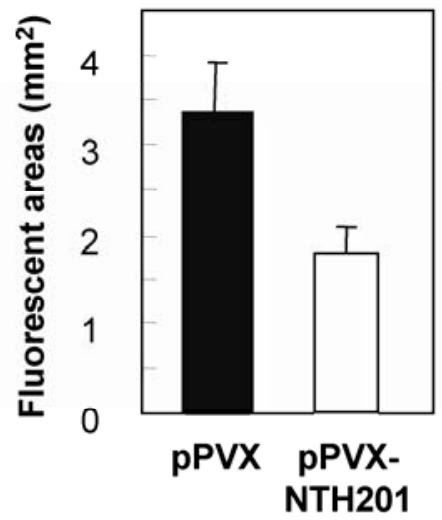

B pPVX
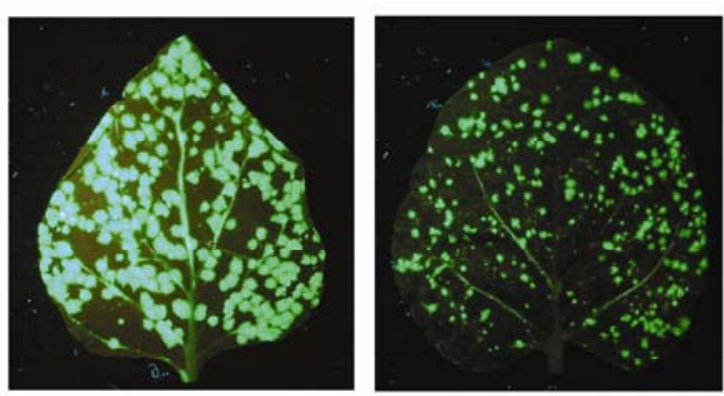

D

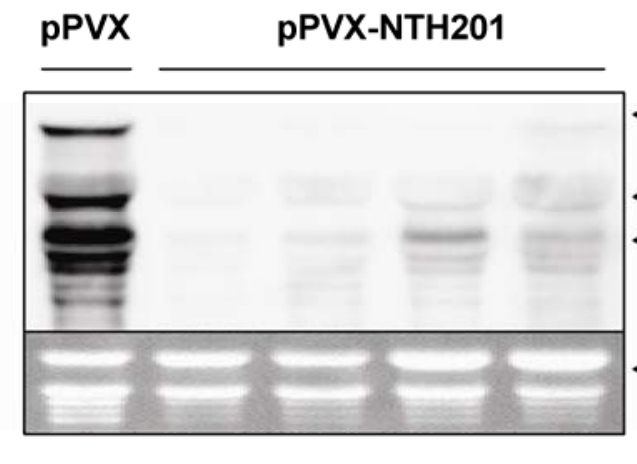

TMV-GFP

VRNA

MP-sgRNA

GFP-sgRNA

rRNA

Fig. 2. Effects of NTH201 silencing in Tobacco mosaic virus (TMV)-infected leaves. A, Efficiency of NTH201 silencing quantified by real-time reversetranscription polymerase chain reaction. The content of NTH201 mRNAs in the upper leaves of Nicotiana benthamiana plants infected with p-Potato virus $X$ (pPVX)-NTH201 was compared with that of the control infected with pPVX vector alone at 3 weeks postinoculation. Data represent average values of three plants with indicated standard deviation values. B, Fluorescent images of the leaves secondarily inoculated with TMV-green fluorescent protein (GFP). The upper leaves of pPVX-infected (left) or pPVX-NTH201-infected (right) $N$. benthamiana plants were secondarily inoculated with TMV-GFP after 3 weeks of the first inoculation and the GFP fluorescent loci were observed after 1 week of the second inoculation. C, Averaged areas of GFP foci with standard deviation bars. The areas of the GFP foci shown in B were quantified using the National Institute of Health image software. D, Accumulation of viral RNA in TMV-GFP-inoculated leaves of NTH201-silencing and nonsilencing plants after 1 week of the second inoculation, analyzed by Northern hybridization using a digoxigenin-labeled RNA probe to detect GFP region. vRNA = TMV-GFP genomic RNA and MP-sgRNA = movement protein-subgenomic RNA. 

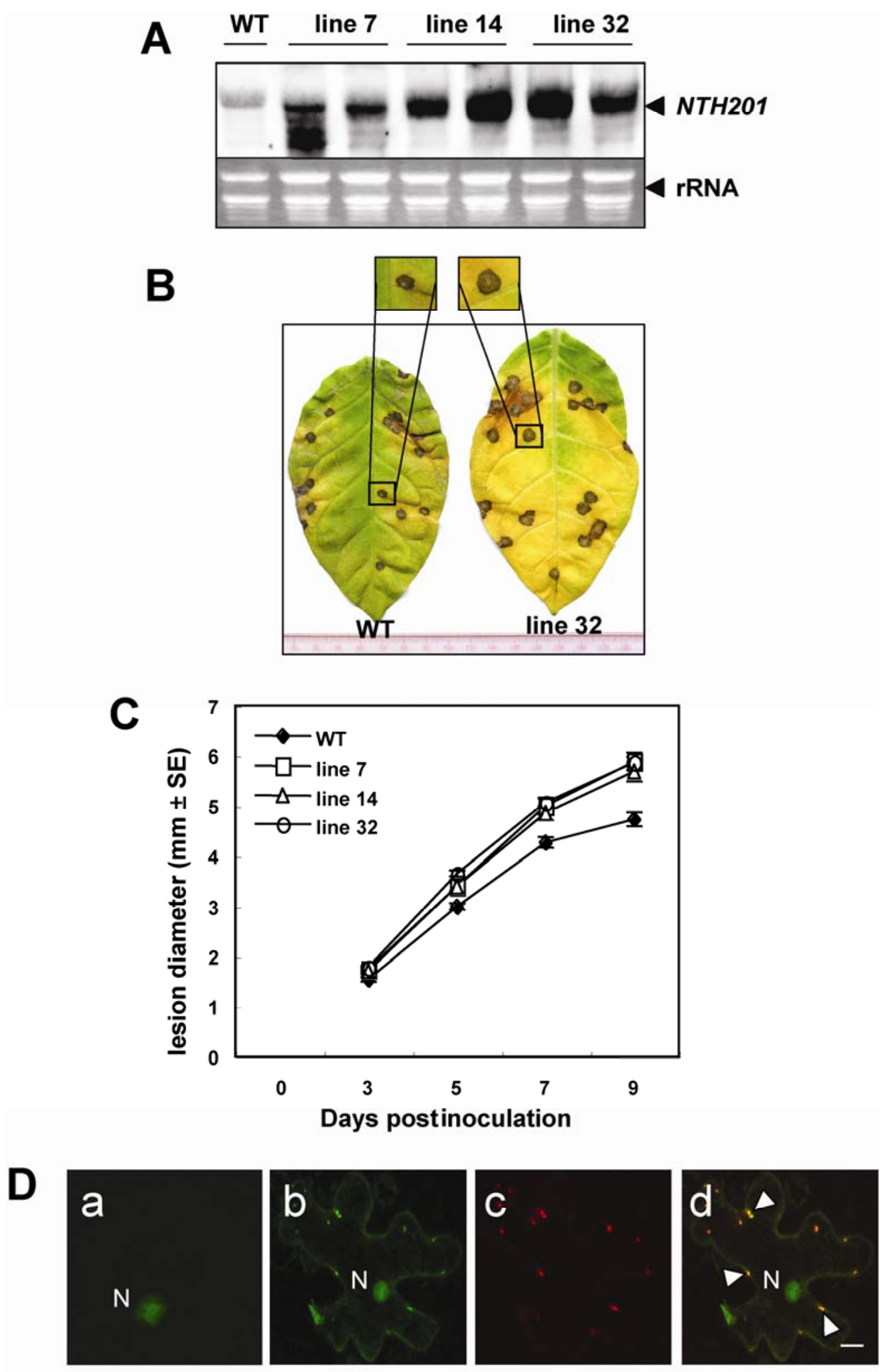

Scale : $10 \mu \mathrm{m}$

Fig. 3. Spread of the local lesions on the NTH201-overexpressing Xanthi nc tobacco leaves inoculated with Tobacco mosaic virus (TMV) and the colocalization of NTH201 and movement protein (MP) in Nicotiana benthamiana epidermal cells. A, Overexpression of NTH201 in three transgenic lines of Xanthi nc tobacco shown by Northern hybridization. WT = wild type; lines 7, 14, and $32=$ transgenic $\mathrm{T}_{1}$ lines of Xanthi nc tobacco. B, Spread of the local lesions on the leaves of WT and transgenic Xanthi nc tobacco plants (line 32) after 9 days of TMV inoculation. C, Diameters of local lesions produced on the leaves of WT and three lines of transgenic Xanthi nc tobacco plants after 3 to 9 days of TMV inoculation. D, Colocalization of NTH201 and MP in N. benthamiana epidermal cells. GFP:NTH201 was transiently expressed solely (a) or together with MP:DsRed (b through d) in N. benthamiana epidermal cells by a particle bombardment and observed under confocal laser scanning microscopy at $24 \mathrm{~h}$ after bombardment. a and b, Green fluorescence by GFP:NTH201; c, red fluorescence by MP:DsRed; and d, merged b and c. N = nucleus and arrowhead = colocalized signal in the plasmodesmata. 
the nonsilenced plants, cell-to-cell spread of TMV-GFP obviously was delayed in NTH201-silenced plants (Fig. 2B). The areas of these GFP foci were quantified using National Institute of Health (NIH) image software and averaged. As a result, in NTH201-silenced plants, GFP foci were approximately half the size of those of the nonsilenced plants (Fig. 2C). The accumulation of viral RNA in TMV-inoculated leaves of NTH201silenced plants revealed a marked reduction compared with that of the nonsilenced plants (Fig. 2D). Moreover, the decrease in the size of GFP foci in NTH201-silenced plants also was observed in another VIGS system based on Tobacco rattle virus (TRV) vector (data not shown). Therefore, it is conceivable that the NTH201 protein is involved in some stages of the TMV infection cycle.

\section{NTH201 facilitated TMV cell-to-cell movement.}

To further clarify the functions of NTH201 in TMV infection, we generated transgenic tobacco Xanthi nc plants overexpressing the full-length $N T H 201$. Xanthi nc tobacco has the $N$ gene for resistance to TMV. These plants produce local necrotic lesions in response to TMV infection. Three independent lines of transgenic $\mathrm{T}_{1}$ plants overexpressing $N T H 201$ were confirmed by Northern hybridization (Fig. 3A). Ectopic expression of class I KNOX genes has been reported previously to cause dramatic morphological changes while that of class II KNOX genes results in no morphological change in tobacco (Nishimura et al. 2000; Sakamoto et al. 1999). The latter was confirmed with

Table 1. Assay of ability of NTH201 to transport green fluoresecent protein (GFP) via plasmodesmata

\begin{tabular}{lcc}
\hline Coexpressed protein & $\begin{array}{c}\text { Cell-to-cell movement } \\
\text { of GFP }(\%)^{\mathbf{b}}\end{array}$ & $\begin{array}{c}\text { Observed cells } \\
\text { (experiments) }\end{array}$ \\
\hline GFP + MP:DsRed & 44.0 & $93(2)$ \\
GFP + MP:DsRed + NTH201 & 32.0 & $72(4)$ \\
GFP + NTH201 & 0 & $64(2)$ \\
\hline a MP:DsRed = fusion protein of movement protein (MP) and DsRed. \\
b The percentage of events where the fluorescent cells were detected \\
around the first bombarded cells at 24 h after bombardment.
\end{tabular}

NTH201-overexpressing plants in this experiment. The spread of the local lesions was measured on the inoculated leaves at 3 to 9 days post-TMV inoculation. At 2 to 3 days postinoculation, the local lesions became visible for both wild-type (WT) and NTH201-overexpressing plants; however, their sizes and rates of spread on the NTH201-transgenic plants were significantly larger and more rapid than those on WT plants. At 9 days postinoculation, expansion of the lesions in all lines of NTH201-transgenic plants was prominently larger than those of WT plants (Fig. 3B and C). Similar results were obtained in the experiments where Wasabi mottle virus (WMoV), another member of the genus Tobamovirus, was inoculated on these transgenic plants. The diameter of local lesions on the leaves of transgenic plants was approximately $1 \mathrm{~mm}$ larger than that of WT plants after 10 days of WMoV inoculation (Supplementary Fig. 1). However, there was no significant difference between WT and NTH201-transgenic plants when PVX, a type virus of the genus Potexvirus, was inoculated (Supplementary Fig. 2). These results suggested that NTH201 might specifically facilitate the virus spread of the genus Tobamovirus.

\section{NTH201 had no ability to self-traffic or to transport GFP between cells.}

There is a possibility that NTH201 may be able to directly enhance the trafficking of TMV MP to the adjacent cells. To investigate this possibility, we checked whether NTH201 could traffic itself or transport GFP between cells in N. benthamiana leaves. The epidermis of detached leaves was bombarded with an expression vector containing the complete coding region of NTH201 fused to GFP (pUC18-GFP:NTH201 or pUC18NTH201:GFP) and combinations of the expression vectors for GFP (pUC18-GFP), MP:DsRed (pUC18-MP:DsRed; $M P$ fused to DsRed), or NTH201 (pUC18-NTH201).

GFP:NTH201 or NTH201:GFP, derived from pUC18GFP:NTH201 or pUC18-NTH201:GFP, respectively, was found to reside only in the nucleus of the bombarded cells (Fig. 3D-a) at $24 \mathrm{~h}$ after bombardment, whereas free GFP signal derived from pUC18-GFP showed diffused localization in the nucleus and the cytoplasm, and MP:DsRed derived from pUC18-

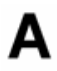

NTH201 lines
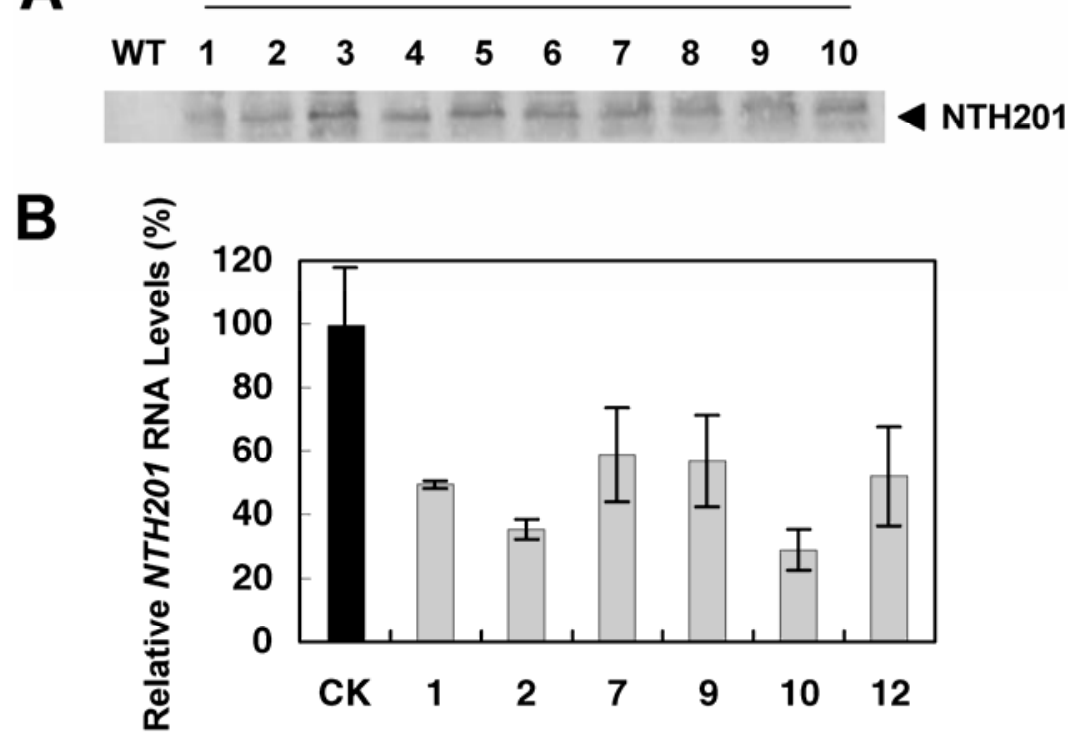

$\Delta$ NTH201 lines

Fig. 4. Assay of NTH201 expression in several transgenic BY-2 cell lines. A, Western blot analysis of NTH201 in several NTH201-transgenic BY-2 cell lines. WT = nontransformed wild-type cell line. B, Real-time reverse-transcription polymerase chain reaction assay of NTH201 mRNA in several $\triangle$ NTH201transgenic BY-2 cell lines. CK = control DsRed transgenic cell line. 
MP:DsRed was observed to spread intercellularly (data not shown). Nuclear localization of the GFP:NTH201 was confirmed by overlapping signal with 4',6-diamidino-2-phenylindole stain (data not shown).

GFP was found only in single epidermal cells when coexpressed with NTH201 whereas GFP moved to the adjacent cells when coexpressed with MP:DsRed at the rate of $44.0 \%$ at $24 \mathrm{~h}$ after bombardment (Table 1). Under these experimental conditions, NTH201 exhibited no accelerating effect on GFP transport by MP. These data indicated that NTH201 lacks the abilities to self-traffic between cells as well as to transport GFP to the neighboring cells.

NTH201 colocalized with MP when coexpressed together.

Next, we observed the subcellular localization of GFP: NTH201 when coexpressed with DsRed-tagged MP (MP: DsRed) in the bombarded epidermal cells of $N$. benthamiana. In contrast to GFP:NTH201 sole expression where it existed only in the nucleus (Fig. 3D-a), GFP:NTH201 coexpressed with MP:DsRed was detected not only in the nucleus but also in the cytoplasm and PD at $24 \mathrm{~h}$ after bombardment (Fig. 3D-b), although MP:DsRed was observed in the cytoplasm and especially in the PD but not in the nucleus (Fig. 3D-c). GFP signals of NTH201 were well merged with DsRed signals of MP except in the nucleus (Fig. 3D-d). These results suggested that MP shifted NTH201 localization from the nucleus to the cytoplasm and PD following colocalization of both proteins.

\section{NTH201 increased the accumulation of MP in TMV-infected protoplasts.}

To examine the effects of NTH201 on the viral RNA replication and protein synthesis in protoplasts, we generated the transgenic tobacco BY-2 cultured cell lines overexpressing NTH201, with silenced NTH201 or overexpressing DsRed as a negative control. Two cell lines overexpressing NTH201 (NTH201 lines 3 and 5) were selected by Western blot assays (Fig. 4A). Also, two cell lines with silenced NTH201 ( $\triangle$ NTH201 line 2 and 10; approximately 50 to $70 \%$ reduction relative to the control) were selected by real-time RT-PCR (Fig. 4B). To gain insight into the effects of NTH201 on viral RNA replication, the protoplasts were isolated from these transgenic BY-2 cells and infected with TMV RNA by electroporation. The amounts of viral genomic RNA and subgenomic RNA (sgRNA) in the infected protoplasts were quantified by real-time RT-PCR analysis at regular intervals after virus inoculation. In the protoplasts overexpressing NTH201 (NTH201 line) or silenced NTH201 ( $\Delta$ NTH201 line), the accumulation patterns of TMV genomic RNA (Fig. 5A) as well as TMV genomic RNA plus MP-sgRNA (Fig. 5B) were almost similar to those in the protoplasts overexpressing DsRed as a control. Next, the kinetics of accumulation of MPs and CPs in these infected protoplasts were examined. NTH201-overexpressing protoplasts indicated similar $\mathrm{CP}$ accumulation to the control protoplasts, whereas $\triangle \mathrm{NTH} 201$-protoplasts showed less CP accumulation (Fig. 5C).

The accumulation kinetics of MP in the control protoplasts were similar to those reported previously in the TMV-infected protoplasts (Reichel and Beachy 2000). However, in the NTH201-overexpressing protoplasts, the increase in MP accumulation was noticeably higher compared with that of the control, whereas it was markedly lower in $\triangle \mathrm{NTH} 201$ protoplasts. Actinomycin D (ActD) is known to increase TMV MP accumulation (Blum et al. 1989). When ActD was added to the protoplasts after inoculation of TMV RNA, MP accumulation in NTH201-overexpressing protoplasts was significantly higher compared with that of the control. These results were repro- ducible in all three independent experiments using different transgenic cell lines. The above experimental results suggested that NTH201 might facilitate specifically MP accumulation but not viral RNA replication in TMV-infected protoplasts.
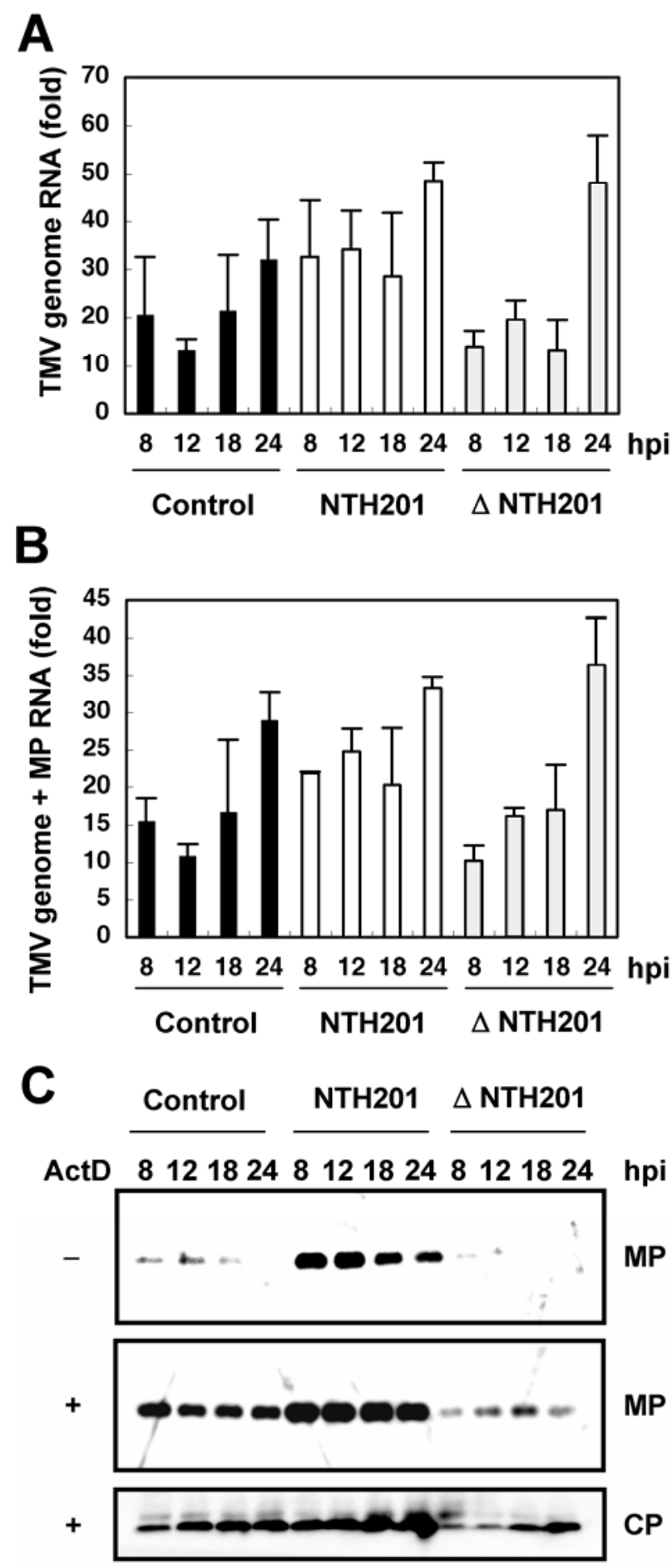

Fig. 5. Accumulation of Tobacco mosaic virus (TMV) RNA, movement protein (MP), and coat protein $(\mathrm{CP})$ in the infected protoplasts of NTH201- and $\triangle$ NTH201-transgenic BY-2 cell lines. A and B, Time course of the relative accumulation rate of $\mathbf{A}$, TMV genomic RNA or $\mathbf{B}$, TMV genomic RNA plus MP-subgenomic RNA in the infected protoplasts quantified by real-time reverse-transcription polymerase chain reaction. Relative TMV RNA levels represent the relative fluorescence ratios of TMV RNA/ubiquitin mRNA. C, Time course of the accumulation of TMV MP and $\mathrm{CP}$ in the infected protoplasts with (+) or without (-) actinomycin D (ActD) exhibited by Western blot analysis using anti-MP antibody or anti$\mathrm{CP}$ antibody; hpi = hours postinoculation . 


\section{NTH201 enhanced the formation} of VRC in TMV-infected protoplasts.

In TMV-infected plant cells, viral RdRp, MP, and host proteins formed VRC to replicate the viral genome and to move between cells (Asurmendi et al. 2004; Kawakami et al. 2004). To determine whether NTH201 affects the formation of VRC in transgenic BY-2 protoplasts, the infectious TMV-MP:GFP RNA expressing GFP fused to MP (MP:GFP) was electroporated into the protoplasts overexpressing NTH201 (NTH201) or silenced NTH201 ( $\triangle \mathrm{NTH} 201)$. The specific localization of MP:GFP-in small punctate structures at early stage of the infection, small irregular bodies, and large irregular bodies at mid to late stages-was found in WT protoplasts (Fig. 6A through $\mathrm{D})$ at 12 to $24 \mathrm{~h}$ after inoculation as reported previously (Heinlein et al. 1998; Mas and Beachy 1999). Small and large irregular bodies were considered as VRC (Asurmendi et al. 2004; Kawakami et al. 2004). In NTH201-overexpressing protoplasts, the localization patterns of MP:GFP (Fig. 6E through $\mathrm{H}$ ) were the same as those in WT protoplasts, but VRC appeared earlier and in greater numbers and sizes than those in WT protoplasts. In $\Delta \mathrm{NTH} 201$-protoplasts, punctate structures and irregular bodies were few and MP:GFP was diffused in cytoplasm at 16 to $22 \mathrm{~h}$ after inoculation (Fig. 6I and J). Although it was unclear whether VRC contained NTH201 or not, these data demonstrated that NTH201 is an indispensable factor for the accumulation of TMV MP and for the formation of VRC.

\section{DISCUSSION}

In the present study, the overexpression of NTH201, a novel class II KNOX tobacco protein, resulted in upregulation of MP accumulation, VRC formation, and virus cell-to-cell movement in TMV-infected cells and plants. In contrast, suppression of NTH201 resulted in downregulation of all of these phenomena.
Other class II KNOX proteins have several homologues and it is possible that NTH201 could have homologues in addition to NTH23 (Sentoku et al. 1998; Serikawa et al. 1996). Thus, it is conceivable that the silencing effects of NTH201 may have affected other unknown homologues. However, this is highly unlikely because we used the vectors containing $3^{\prime}$-UTR specific for NTH201 (Burch-Smith et al., 2004). The overexpressing effects of NTH201 were undoubtedly specific for itself.

It also was shown that NTH201 had no self-trafficking or GFP-transporting ability and colocalized with MP as seen in the transient expression experiments. Class II KNOX proteins such as tobacco NTH23 and Arabidopsis KNAT3 also have no trafficking ability (Kim et al. 2005; Sentoku et al. 1998). NTH23 was reported to express at the basal part of leaf blade primordial (Sentoku et al. 1998). KNAT3 was expressed in several tissues and at various times during plant development, indicating that it plays several different roles in plant (Serikawa et al. 1997).

Although the authentic physiological function and expression pattern of NTH201 is unknown at present, what is the role of NTH201 in the TMV-infected cells? NTH201 was observed to migrate from the nucleus to the cytoplasm and PD followed by colocalization with MP when expressed together with MP. It has been reported that P22 MP of Tomato bushy stunt virus (TBSV) interacted with homeodomain leucine-zipper protein (Desvoyes et al. 2002); however, no direct binding between NTH201 and TMV MP was detected by the yeast two-hybrid assay (data not shown). Therefore, it is possible that NTH201 might bind indirectly to MP via another host protein that could affect, solely or together with NTH201, some activities of MP.

NTH201 had no ability to self-traffic or transport GFP into neighboring cells but apparently could facilitate TMV cell-tocell movement in the NTH201-overexpressing plants. Such a facilitating effect was not detected in the cells where NTH201 was transiently expressed. Consequently, the preceding expres-
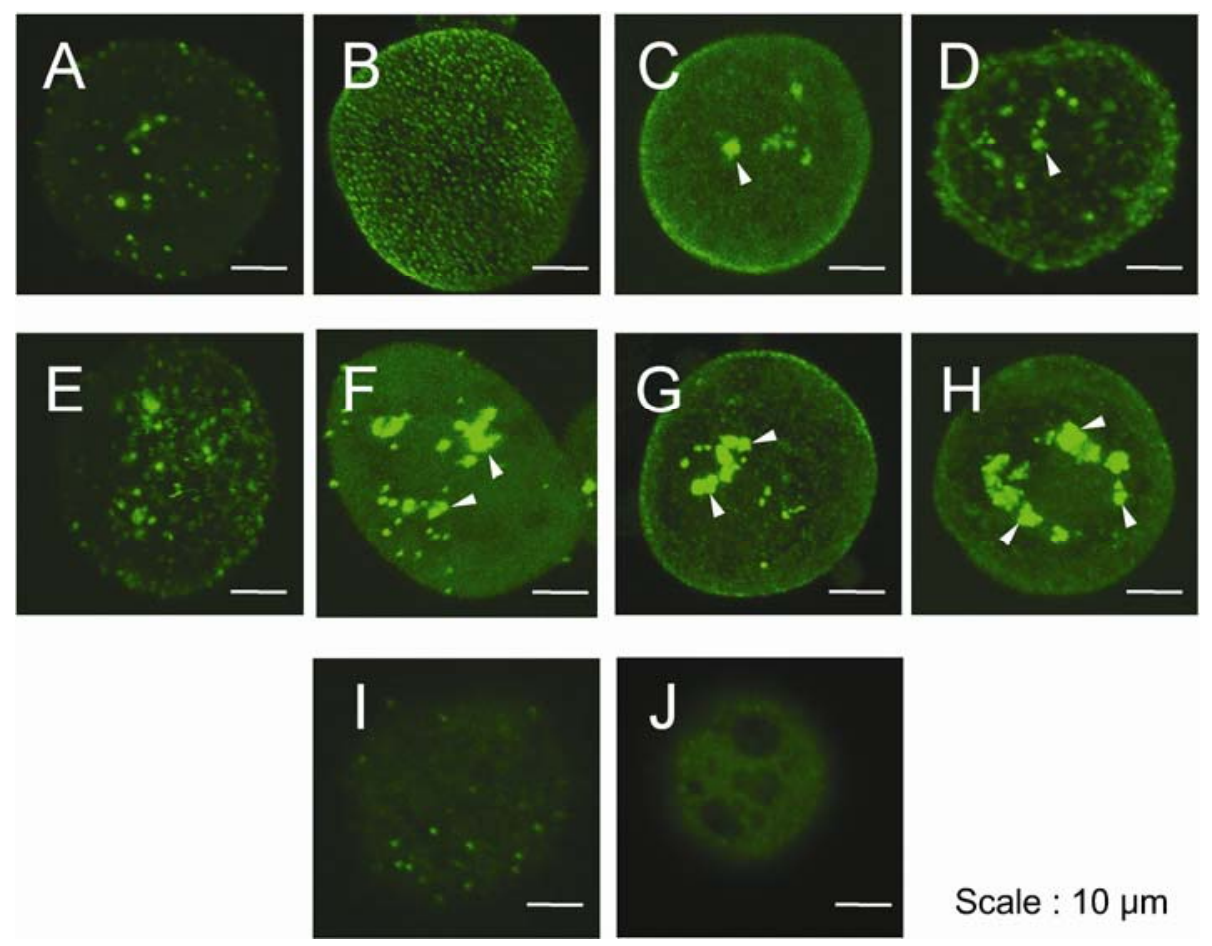

Scale : $10 \mu \mathrm{m}$

Fig. 6. Effects of the overexpression or silencing of NTH201 on the virus replication complex (VRC) formation during Tobacco mosaic virus (TMV) infection in tobacco BY-2 protoplasts. NTH201-overexpressing or -silenced protoplasts were inoculated with TMV-movement protein:green fluorescent protein RNA and observed under confocal laser scanning microscopy at regular time intervals after inoculation. A through $\mathbf{D}$, wild type protoplasts; $\mathbf{E}$ through $\mathbf{H}$, NTH201-overexpressing protoplasts; I and J, NTH201-silenced protoplasts. Time intervals: A and E, 12 h postinoculation (hpi); B, F, and I, 16 hpi; C, G and $\mathbf{J}, 22 \mathrm{hpi}$; $\mathbf{D}$ and $\mathbf{H}, 24 \mathrm{hpi}$; and arrowhead = VRC. 
sion of NTH201 might be necessary before the virus infection to confer this effect. In the NTH201-overexpressing cells infected with TMV, the increased accumulation of MPs but not of viral genomic RNAs or MP-sgRNAs and the accelerated formation of VRC were demonstrated. This shows that the increased accumulation of MPs was not dependent on that of newly synthesized MP-mRNAs but was likely dependent on the increased stability of MP. MP was known to be expressed transiently and rapidly degraded by the $26 \mathrm{~S}$ proteasome at an early infection stage in the cells (Reichel and Beachy 2000; Watanabe et al. 1984), whereas ActD increased TMV MP accumulation (Blum et al. 1989), which also was confirmed in the present study. The MP accumulation level in NTH201overexpressing protoplasts without ActD was almost the same as that in nontransgenic protoplasts with ActD. Hence, it is possible that NTH201 might stabilize the active MP molecules indirectly by assisting MPs to fold their tertiary structure or by protecting their degradation by the $26 \mathrm{~S}$ proteasome. Because it is conceivable that NTH201 may be a transcription factor like other KNOX proteins, the products of NTH201 target genes might directly regulate these actions.

VRC of TMV were reported to include MP, RdRp, and some host proteins as well as viral RNA and suggested to traffic to the adjacent cells (Asurmendi et al. 2004; Kawakami et al. 2004). Therefore, it seems reasonable to suppose a possibility that the increase in active MP molecules mediated indirectly by NTH201 could facilitate VRC formation and its intercellular traffic as well as virus multiplication in the infected cells, which results in rapid virus cell-to-cell movement in the tissues.

\section{MATERIALS AND METHODS}

\section{Plant materials.}

$N$. benthamiana was grown in a temperature-controlled greenhouse and 4- to 5-week-old plants were used for the silencing experiments. Nontransgenic $N$. tabacum cv. Xanthi plants and transgenic $N$. tabacum cv. Xanthi nc plants overexpressing NTH201 were grown in a growth chamber with a cycle of $16 \mathrm{~h}$ of light and $8 \mathrm{~h}$ of darkness at $25^{\circ} \mathrm{C}$.

\section{Cloning of NTH201 gene.}

Total RNA was prepared from tobacco leaves (N. tabacum cv. Xanthi) using RNeasy midi kit (Qiagen, Valencia, CA, U.S.A.) according to the manufacturer's instructions, and their cDNAs were synthesized using SuperScript III reverse transcriptase (Invitrogen Corp., Carlsbad, CA, U.S.A.) and oligo(dT) ${ }_{20}$ according to the manufacturer's instructions. A partial NTH2O1 cDNA was amplified with Phusion high-fidelity DNA polymerase (New England Biolabs, Ipswich, MA, U.S.A.) from them using a set of degenerate primers, $5^{\prime}-\mathrm{CG}(\mathrm{C} / \mathrm{T}) \mathrm{GT}(\mathrm{C} / \mathrm{T}) \mathrm{CA}$ TGCAATGGAAGC-3' and 5'-TGGATTGCT(A/G)TGCCA(A/ G)TTCCT-3', designed for the conserved sequences of class II KNOX genes, Arabidopsis KNAT3 and KNAT4 (Serikawa et al. 1997) and tomato LeT12 (Janssen et al. 1998). The remaining $5^{\prime}$ and $3^{\prime}$ ends of the complete NTH2O1 cDNA were obtained from tobacco total RNA pool by RNA ligase-mediated oligocapping 5'- and 3'-RACE methods using GeneRacer Kit (Invitrogen) and Phusion High-Fidelity DNA Polymerase with appropriate gene-specific primers according to the manufacturer's instructions. Then, a full-length NTH2O1 cDNA clone was sequenced using an ABI PRISM 3100 Genetic Analyzer (Applied Biosystems, Foster City, CA, U.S.A.). DNA and predicted protein sequence analyses were performed with the BLAST algorithm at the National Center for Biotechnology Information (NCBI, Bethesda, MA, U.S.A.).

Multiple alignment of several KNOX proteins was performed based on CLUSTAL $\mathrm{W}$ and the phylogenic tree was calculated on their total amino acid sequences using CLUSTAL W and NJPlot programs.

\section{VIGS of NTH201.}

For gene silencing of endogenous NTH201, we used a PVXbased expression vector. Briefly, the Gateway reading frame cassette A (Invitrogen) was inserted into the SmaI site of $\mathrm{pCXV}$, to generate pPVX as a gateway destination vector. D. Baulcombe gave us plasmid pCXV (Baulcombe et al. 1995), in which PVX cDNA was modified to express an exogenous gene inserted between the CaMV 35S promoter and the nopaline synthase gene terminator. Then, the partial 3'-UTR sequence of the NTH2O1 gene was cloned into the multicloning site of the pENTR 1A (Invitrogen) and designated pENTER-NTH201 as an entry vector. The $3^{\prime}$-UTR of NTH201 was amplified using the following primers: primer 5' NTH201-UTR including a BamHI site, 5'-TCGGGATCCATAGCAATCCATCGAC ATCG-3'; and primer $3^{\prime}$ NTH201-UTR including a KpnI site, 5'-TCCGGTACCAACAGGGGAAATCGTTCATACC-3'. The gene-silencing vector pPVX-NTH201 was generated by Gateway LR Clonase (Invitrogen) recombination reaction between the pENTR-NTH201 and the pPVX according to the manufacturer's instructions.

The plasmid DNAs, pPVX-NTH201 or pPVX as a control, were inoculated directly into the leaves of $N$. benthamiana plants using a hand-held particle delivery system (Helios Gene Gun system; Bio-Rad, Hercules, CA, U.S.A.) according to the manufacturer's instructions. At 3 weeks postinoculation, the upper leaves became systemically infected with the recombinant pPVXs. These upper leaves were secondarily inoculated with TMV-GFP, a recombinant TMV (U1 strain) expressing GFP together with RdRp, MP, and heterologous CP of Tobacco mild green mosaic virus (U5 variant). To prepare the inoculum TMV-GFP, the in vitro transcripts of p30B-GFP (Shivprasad et al. 1999), a gift from W. O. Dawson, were inoculated on $N$. benthamiana plants and the propagated virus particles were partially purified as previously described (Canto and Palukaitis 2002).

At 1 week postinoculation of TMV-GFP on the silenced leaves, GFP-derived fluorescent images on the infected plants were examined nondestructively by visualization or photography with a hand-held long-wave UV lamp (366 nm) and digital camera CAMEDIA C-4040 ZOOM (Olympus, Tokyo). The areas of these GFP foci were quantified using Adobe Photoshop 7.0 (Adobe Systems, Mountain View, CA, U.S.A.) and NIH image 1.63 (NIH, Bethesda, MD, U.S.A.) software and averaged using Microsoft Excel (Microsoft, Redmond, WA, U.S.A.).

To verify the reduction of NTH201 mRNA, a set of primers, 5'-ATGGCTTGTTGGGAGCTAGA-3' and 5'-TCTGCCTGGT CATCATC-3', were used for the real-time RT-PCR analysis. These primers anneal to the sequences of outside region of NTH2Ol genes targeted for silencing. The primers described below were used for ubiquitin (UBI) mRNA internal control; UBI forward primer: 5'-CGGCATGCTTAACACATGCA-3', and UBI reverse primer: 5'-AGCCGTTTCCAGCTGTTGTT C-3'. Total RNA was extracted from post-inoculated leaves, and cDNA was synthesized from $1 \mu \mathrm{g}$ of total RNA by using the High-Capacity cDNA Archive Kit (Applied Biosystems). Subsequently, the NTH2O1 gene was amplified using SYBER Green PCR Master Mix (Applied Biosystems) and analyzed by using an ABI PRISM 7700 Sequence Detection System (Applied Biosystems) according to the manufacturer's instructions.

The accumulation of TMV-GFP RNA was analyzed by Northern hybridization using a digoxigenin-labeled RNA probe to detect the GFP region. 
NTH201-overexpressing transgenic plants and TMV infection.

To overexpress NTH201 in tobacco plants, full-length of NTH2O1 was inserted into the multicloning site of pBI121 vector (Clontech, Mountain View, CA, U.S.A.). Transgenic lines of $N$. tabaccum cv. Xanthi nc that constitutively overexpress NTH201 were generated via Agrobacterium-mediated leafdisk transformation as described (An 1987; Horsch et al. 1985). Total RNA from $T_{1}$ transgenic plants was purified, and $10 \mu \mathrm{g}$ of total RNA was analyzed by Northern hybridization to confirm the overexpression of NTH201. For inoculation tests, 6-week-old transgenic $\mathrm{T}_{1}$ plants were mechanically inoculated with TMV (OM strain) (Watanabe et al. 1999) using Carborundum. At 3 to 9 days after inoculation, the sizes of necrotic local lesions were measured.

\section{Assay of NTH201 traffic ability and detection of NTH201 localization.}

To assay the NTH201 self-traffic ability, a full coding region of NTH2O1 was fused with GFP at the N-terminal side or Cterminal side and the fusion gene was inserted into pUC18based 35S-driven GFP-expression vector to construct pUC18GFP:NTH201 or pUC18-NTH201:GFP following a bombardment into $N$. benthamiana leaves using a PDS1000/He system (Bio-Rad). In these vectors, a synthetic GFP S65T mutant derived from p35S-sGFP (gift from Y. Niwa) was used instead of native GFP and the fusion proteins were spaced by two to four glycine linkers. To assay the NTH201 ability to transport GFP via PD, pUC18-based 35S-driven plasmids which express GFP (pUC18-GFP), MP fused to a red fluorescent protein (DsRed2) (Clontech) (pUC18-MP:DsRed), or NTH201 (pUC18-NTH201) were constructed and the combinations of the three plasmids were cobombarded as follows. Briefly, $1 \mu \mathrm{g}$ of plasmid DNA was combined with $10 \mu \mathrm{l}$ of 1.0 -micron prepared gold particles (Bio-Rad). The coated gold particles were introduced to the abaxial side of the leaf with a PDS-1000/He system with a 900-psi rupture disk (Bio-Rad). Following bombardment, leaf disks were incubated in the dark in a petri dish with Murashige and Skoog-agar medium.

\section{Fluorescence microscopy.}

Confocal laser scanning microscopy (CLSM) was conducted with a Zeiss LSM 5 PASCAL (Carl Zeiss, Oberkochen, Germany), according to the manufacturer's instructions. Data of GFP signals were acquired using a 488-nm laser line of an argon laser (Carl Zeiss) with a 505- to 530-nm emission filter. DsRed signals were acquired using a 543-nm laser line of a helium neon laser (Carl Zeiss) with a 560- to 615-nm emission filter.

Transformation of suspension-cultured tobacco BY-2 cells.

The full-length coding region of NTH2O1 and the inverted construct of 3'-UTR of NTH2O1 or DsRed2 gene (Clontech) as a control were inserted into the multicloning sites of binary vector pBI121 to construct pBI-NTH201, pBI- $\triangle$ NTH201, or pBI-DsRed, respectively. For silencing of the endogenous genes, an intron containing inverted construct was known to efficiently silence the target genes (Smith et al. 2000; Wesley et al. 2001). For pBI- $\Delta$ NTH201, we amplified the second intron of tobacco actin gene (X63603), and the 3' UTR corresponding to nucleotides 1,269 to 1,551 of $N T H 201$ was ligated to $5^{\prime}$ and $3^{\prime}$ arms of this intron to be transcribed as a hairpin RNA containing an inverted repeat.

These constructs were transferred to Agrobacterium tumefaciens LBA4404 by electroporation as described (Nagel et al. 1990), and the transformant bacteria were used to transform the suspension-cultured tobacco BY-2 cells, essentially as de- scribed by An (1987). The transgenic tobacco BY-2 cells were selected on BY-2 agar medium (Murashige and Skoog salts at $4.3 \mathrm{~g} / \mathrm{liter}$, sucrose at $30 \mathrm{~g} / \mathrm{liter}, \mathrm{KH}_{2} \mathrm{PO}_{4}$ at $180 \mathrm{mg} / \mathrm{liter}$, myoinositol at $100 \mathrm{mg} / \mathrm{liter}$, thiamine $\mathrm{HCl}$ at $1 \mathrm{mg} / \mathrm{liter}, 2,4-\mathrm{D}$ at $0.2 \mathrm{mg} / \mathrm{liter}$, and Gelrite at $4 \mathrm{~g} / \mathrm{liter}$ ) (Nagata et al. 1981) containing kanamycin at $50 \mathrm{mg} /$ liter and claforan at $500 \mathrm{mg} / \mathrm{liter}$. Then, several transgenic BY-2 cell lines were checked by PCR, selected by Western blot or real-time RT-PCR analyses, and maintained in liquid culture at $28^{\circ} \mathrm{C}$ in the dark on a rotary shaker at $120 \mathrm{rpm}$. Every 7 days, $2 \mathrm{ml}$ of culture was transferred to a new flask containing BY-2 medium.

\section{Quantification of viral RNAs and proteins in TMV-infected protoplasts.}

Tobacco protoplasts were prepared from BY-2 suspension cell cultures as described previously (Watanabe et al. 1987) and $2 \times 10^{6}$ protoplasts suspended in an electroporation buffer $(5 \mathrm{mM}$ morpholineethanesulfonic acid, $70 \mathrm{mM} \mathrm{KCl}$, and 0.4 M D-mannitol) were inoculated with $2.5 \mu \mathrm{g}$ of purified RNA of TMV (OM strain) via electroporation using a Gene Pulser II (Bio-Rad) at $750 \mathrm{~V} / \mathrm{cm}$ and $100 \mu \mathrm{F}$ according to the manufacturer's instructions. After the inoculation, protoplasts were resuspended in $10 \mathrm{ml}$ of BY-2 suspension medium containing $0.4 \mathrm{M}$ D-mannitol, and 1-ml aliquots in $35-\mathrm{mm}$ petri dishes were cultured in the dark from 8 to $24 \mathrm{~h}$ at $28^{\circ} \mathrm{C}$ at $60 \mathrm{rpm}$. ActD $(30 \mu \mathrm{g} / \mathrm{ml})$, which increases the accumulation of TMVMP (Blum et al. 1989), was added to the protoplast after the inoculation from a stock solution prepared with dimethyl sulfoxide as a solvent.

To quantify the amounts of viral genomic RNA and MPsgRNA in inoculated protoplasts, total RNA from $2 \times 10^{5}$ protoplasts was extracted using $100 \mu \mathrm{l}$ of ISOGEN (Nippon Gene, Tokyo) according to the manufacturer's instructions. We analyzed the accumulation of TMV genomic RNA by using realtime RT-PCR with forward primer 126K/1293 (5'-ACCAGGC GAAAGCTCTTACA-3') and reverse primer $126 \mathrm{~K} / 1440\left(5^{\prime}-\right.$ TGCAGGTAAAACGTCATGGA-3'). These $126 \mathrm{~K}$ primers amplify only the RNA-dependent RNA polymerase coding region of TMV genomic RNA. For MP-sgRNA, forward primer MP/5147 (5'-CAATTGCAGAGGAGGTGTGA-3') and reverse primer MP/5251 (5'-GGGAACGACCTTGAACTGAA-3') were used which amplify both TMV genomic RNA and MPsgRNA. UBI mRNA was used as an internal control as mentioned above.

To quantify the amounts of viral MP and $\mathrm{CP}$ proteins in infected protoplasts, $2 \times 10^{5}$ protoplasts were mixed, boiled, and solubilized with $100 \mu \mathrm{l}$ of $2 \times$ sodium dodecyl sulfate (SDS) sample buffer (Tris-HCl/SDS, pH 6.8; 20\% glycerol; $4 \%$ SDS; 2-mercaptoethanol; and $0.001 \%$ bromophenol blue). Then, $1 / 10$ vol of the solution was loaded in the SDS-12.5\% polyacrylamide gel electrophoresis, and the accumulation of viral proteins was analyzed by Western blot using anti-MP polyclonal antibody or anti-CP monoclonal antibody (each $1 / 5,000$ dilution). Western blot analysis was conducted using ECL Plus Western blotting detection reagents (GE Healthcare, Buchinghamshire, U.K.), and signal detection was acquired using an LAS-1000 Imaging System (Fujifilm, Tokyo) according to the manufacturer's instructions.

\section{Effect of NTH201 on the MP accumulation and VRC formation in TMV-infected protoplasts.}

We constructed TMV cDNA clones (pTMV-MP:GFP) expressing GFP fused to MP based on pT7-TMVom, a T7 promoter driven expression vector for an infectious in vitro transcript of TMV (OM strain). For this, we amplified an MP gene fragment from pT7-TMVom using the following primers: forward primer, including NcoI site, 5'-TCGTCATATGGCTCTA 
GTTGTTAAAGGAAAAG-3'; and reverse primer, including AvrII site, 5'-AAAGGGCCCTGCAGCCTAGGAAACGAATC CGATTCGGCGA- $3^{\prime}$. Then, an AvrII-KpnI fragment encoding the GFP S65T region amplified from p35S-sGFP was fused to the NcoI-AvrII MP fragment to be translated as a fusion protein. This fused fragment was cloned between $N c o \mathrm{I}$ and $K p n \mathrm{I}$ sites of pT7-TMVom, and the resultant clone lacking the CP gene was designated as pTMV-MP:GFP. For virus inoculation to the protoplasts, KpnI-linearized pTMV-MP:GFP was transcribed in vitro using a MEGAscript T7 kit (Ambion, Austin, TX, U.S.A.), including cap analogue (10:1 in GTP ratio). Capped transcripts were introduced into BY-2 protoplasts by electroporation. The accumulation of MP:GFP and formation of VRC in infected protoplasts were observed under a CLSM at regular culture time intervals.

\section{ACKNOWLEDGMENTS}

This work was supported by a Grant-in-Aid (12052207) for Scientific Research on Priority Area from Ministry of Education, Culture, Sports, Science and Technology, Japan, and a Grant-in-Aid (13854004) from the Japan Society for the Promotion of Science. We thank D. C. Baulcombe for providing the infectious PVX cDNA clone pCXV, W. O. Dawson for the infectious TMV cDNA clone p30B-GFP, and Y. Niwa for the p35SsGFP.

\section{LITERATURE CITED}

An, G. 1987. Binary Ti vectors for plant transformation and promoter analysis. Methods Enzymol. 153:292-305.

Ashby, J., Boutant, E., Seemanpillai, M., Sambade, A., Ritzenthaler, C., and Heinlein, M. 2006. Tobacco mosaic virus movement protein functions as a structural microtubule-associated protein. J. Virol. 80:83298344.

Asurmendi, S., Berg, R. H., Koo, J. C., and Beachy, R. N. 2004. Coat protein regulates formation of replication complexes during tobacco mosaic virus infection. Proc. Natl. Acad. Sci. U.S.A. 101:1415-1420.

Baulcombe, D. C., Chapman, S., and Santa Cruz, S. 1995. Jellyfish green fluorescent protein as a reporter for virus infections. Plant J. 7:10451053.

Bharathan, G., Janssen, B. J., Kellogg, E. A., and Sinha, N. 1999. Phylogenetic relationships and evolution of the KNOTTED class of plant homeodomain proteins. Mol. Biol. Evol. 16:553-563.

Blum, H., Gross, H. J., and Beier, H. 1989. The expression of the TMVspecific $30-\mathrm{kDa}$ protein in tobacco protoplasts is strongly and selectively enhanced by actinomycin. Virology 169:51-61.

Boevink, P., and Oparka, K. J. 2005. Virus-host interactions during movement processes. Plant Physiol. 138:1815-1821.

Burch-Smith, T. M., Anderson, J. C., Martin, G. B., and Dinesh-Kumar, S. P. 2004. Applications and advantages of virus-induced gene silencing for gene function studies in plants. Plant J. 39:734-746.

Burton, R. A., Gibeaut, D. M., Bacic, A., Findlay, K., Roberts, K., Hamilton, A., Baulcombe, D. C., and Fincher, G. B. 2000. Virus-induced silencing of a plant cellulose synthase gene. Plant Cell 12:691-706.

Canto, T., and Palukaitis, P. 2002. Novel N gene-associated, temperatureindependent resistance to the movement of tobacco mosaic virus vectors neutralized by a cucumber mosaic virus RNA1 transgene. J. Virol. 76:12908-12916.

Chen, M. H., and Citovsky, V. 2003. Systemic movement of a tobamovirus requires host cell pectin methylesterase. Plant J. 35:386-392.

Chen, M. H., Sheng, J., Hind, G., Handa, A. K., and Citovsky, V. 2000. Interaction between the tobacco mosaic virus movement protein and host cell pectin methylesterases is required for viral cell-to-cell movement. EMBO (Eur. Mol. Biol. Organ.) J. 19:913-920.

Chen, M. H., Tian, G. W., Gafni, Y., and Citovsky, V. 2005. Effects of calreticulin on viral cell-to-cell movement. Plant Physiol. 138:1866-1876.

Citovsky, V., Knorr, D., Schuster, G., and Zambryski, P. 1990. The P30 movement protein of tobacco mosaic virus is a single-strand nucleic acid binding protein. Cell 60:637-647.

Citovsky, V., Wong, M. L., Shaw, A. L., Prasad, B. V., and Zambryski, P. 1992. Visualization and characterization of tobacco mosaic virus movement protein binding to single-stranded nucleic acids. Plant Cell 4:397411.

Deshpande, A. D., Ramakrishna, W., Mulay, G. P., Gupta, V. S., and Ranjekar, P. K. 1999. Phylogenetic classification and molecular evolution of knotted1 homeobox genes. Theor. Appl. Genet. 99:203-209.
Desvoyes, B., Faure-Rabasse, S., Chen, M. H., Park, J. W., and Scholthof, H. B. 2002. A novel plant homeodomain protein interacts in a functionally relevant manner with a virus movement protein. Plant Physiol. 129:1521-1532.

Dorokhov, Y. L., Makinen, K., Frolova, O. Y., Merits, A., Saarinen, J., Kalkkinen, N., Atabekov, J. G., and Saarma, M. 1999. A novel function for a ubiquitous plant enzyme pectin methylesterase: The host-cell receptor for the tobacco mosaic virus movement protein. FEBS (Fed. Eur. Biochem. Soc.) Lett. 461:223-228.

Gallagher, K. L., and Benfey, P. N. 2005. Not just another hole in the wall: Understanding intercellular protein trafficking. Genes Dev. 19:189-195.

Hake, S., Smith, H. M., Holtan, H., Magnani, E., Mele, G., and Ramirez, J. 2004. The role of knox genes in plant development. Annu. Rev. Cell Dev. Biol. 20:125-151.

Heinlein, M., Epel, B. L., Padgett, H. S., and Beachy, R. N. 1995. Interaction of tobamovirus movement proteins with the plant cytoskeleton. Science 270:1983-1985.

Heinlein, M., Padgett, H. S., Gens, J. S., Pickard, B. G., Casper, S. J., Epel, B. L., and Beachy, R. N. 1998. Changing patterns of localization of the tobacco mosaic virus movement protein and replicase to the endoplasmic reticulum and microtubules during infection. Plant Cell 10:1107-1120.

Hirashima, K., and Watanabe, Y. 2001. Tobamovirus replicase coding region is involved in cell-to-cell movement. J. Virol. 75:8831-8836.

Hirashima, K., and Watanabe, Y. 2003. RNA helicase domain of tobamovirus replicase executes cell-to-cell movement possibly through collaboration with its nonconserved region. J. Virol. 77:12357-12362.

Horsch, R. B., Fry, J. E., Hoffmann, N. L., Eichholtz, D., Rogers, S. G., and Fraley, R. T. 1985. A simple and general method for transferring genes into plants. Science 277:1229-1231.

Janssen, B. J., Williams, A., Chen, J. J., Mathern, J., Hake, S., and Sinha N. 1998. Isolation and characterization of two knotted-like homeobox genes from tomato. Plant Mol. Biol. 36:417-425.

Kawakami, S., Watanabe, Y., and Beachy, R. N. 2004. Tobacco mosaic virus infection spreads cell to cell as intact replication complexes. Proc. Natl. Acad. Sci. U.S.A. 101:6291-6296.

Kerstetter, R., Vollbrecht, E., Lowe, B., Veit, B., Yamaguchi, J., and Hake, S. 1994. Sequence analysis and expression patterns divide the maize knotted1-like homeobox genes into two classes. Plant Cell 6:18771887.

Kim, J. Y., Yuan, Z., Cilia, M., Khalfan-Jagani, Z., and Jackson, D. 2002. Intercellular trafficking of a KNOTTED1 green fluorescent protein fusion in the leaf and shoot meristem of Arabidopsis. Proc. Natl. Acad Sci. U.S.A. 99:4103-4108.

Kim, J. Y., Yuan, Z., and Jackson, D. 2003. Developmental regulation and significance of KNOX protein trafficking in Arabidopsis. Development 130:4351-4362.

Kim, J. Y., Rim, Y., Wang, J., and Jackson, D. 2005. A novel cell-to-cell trafficking assay indicates that the KNOX homeodomain is necessary and sufficient for intercellular protein and mRNA trafficking. Genes Dev. 19:788-793.

Kragler, F., Curin, M., Trutnyeva, K., Gansch, A., and Waigmann, E. 2003. $\mathrm{MPB} 2 \mathrm{C}$, a microtubule-associated plant protein binds to and interferes with cell-to-cell transport of Tobacco mosaic virus movement protein Plant Physiol. 132:1870-1883.

Lee, J. Y., Yoo, B. C., Rojas, M. R., Gomez-Ospina, N., Staehelin, L. A., and Lucas, W. J. 2003. Selective trafficking of non-cell-autonomous proteins mediated by NtNCAPP1. Science 299:392-396.

Lee, J. Y., Taoka, K., Yoo, B. C., Ben-Nissan, G., Kim, D. J., and Lucas, W. J. 2005. Plasmodesmal-associated protein kinase in tobacco and Arabidopsis recognizes a subset of non-cell-autonomous proteins. Plant Cell 17:2817-2831.

Lucas, W. J. 2006. Plant viral movement proteins: Agents for cell-to-cell trafficking of viral genomes. Virology 344:169-184.

Lucas, W. J., Bouche-Pillon, S., Jackson, D. P., Nguyen, L., Baker, L., Ding, B., and Hake, S. 1995. Selective trafficking of KNOTTED1 homeodomain protein and its mRNA through plasmodesmata. Science 270:1980-1983.

Mas, P., and Beachy, R. N. 1999. Replication of Tobacco mosaic virus on endoplasmic reticulum and role of the cytoskeleton and virus movement protein in intracellular distribution of viral RNA. J. Cell Biol. 147:945958.

McLean, B. G., Zupan, J., and Zambryski, P. C. 1995. Tobacco mosaic virus movement protein associates with the cytoskeleton in tobacco cells Plant Cell 7:2101-2114.

Nagata, T., Takebe, I., and Matsui, C. 1981. Delivery of tobacco mosaic virus RNA into plant protoplasts mediated by reverse-phase evaporation vesicles (liposomes). Mol. Gen. Genet. 184:161-165.

Nagel, R., Elliott, A., Masel, A., Birch, R. G., and Manners, J. M. 1990. Electroporation of binary Ti plasmid vector into Agrobacterium tume- 
faciens and Agrobacterium rhizogenes. FEMS (Fed. Eur. Microbiol. Soc.) Microbiol. Lett. 67:325-328.

Nishimura, A., Tamaoki, M., Sakamoto, T., and Matsuoka, M. 2000. Overexpression of tobacco knotted1-type class1 homeobox genes alters various leaf morphology. Plant Cell Physiol. 41:583-590.

Reichel, C., and Beachy, R. N. 2000. Degradation of tobacco mosaic virus movement protein by the $26 \mathrm{~S}$ proteasome. J. Virol. 74:3330-3337.

Reiser, L., Sánchez-Baracaldo, P., and Hake, S. 2000. Knots in the family tree: Evolutionary relationships and functions of knox homeobox genes. Plant Mol. Biol. 42:151-166.

Ruiz, M. T., Voinnet, O., and Baulcombe, D. C. 1998. Initiation and maintenance of virus-induced gene silencing. Plant Cell 10:937-946.

Saito, T., Yamanaka, K., Watanabe, Y., Takamatsu, N., Meshi, T., and Okada, Y. 1989. Mutational analysis of the coat protein gene of tobacco mosaic virus in relation to hypersensitive response in tobacco plants with the $\mathrm{N}^{\prime}$ gene. Virology 173:11-20.

Saito, T., Yamanaka, K., and Okada, Y. 1990. Long-distance movement and viral assembly of tobacco mosaic virus mutants. Virology 176:329336

Sakamoto, T., Nishimura, A., Tamaoki, M., Kuba, M., Tanaka, H., Iwahori, S., and Matsuoka, M. 1999. The conserved KNOX domain mediates specificity of tobacco KNOTTED1-type homeodomain proteins. Plant Cell 11:1419-1432.

Sentoku, N., Tamaoki, M., Nishimura, A., and Matsuoka, M. 1998. The homeobox gene NYH23 of tobacco is expressed in the basal region of leaf primordial. Biochim. Biophys. Acta 1399:203-208.

Serikawa, K. A., Martinez-Laborda, A., and Zambryski, P. 1996. Three knotted1-like homeobox genes in Arabidopsis. Plant Mol. Biol. 32:673683

Serikawa, K. A., Martinez-Laborda, A., Kim, H. S., and Zambryski, P. C. 1997. Localization of expression of KNAT3, a class 2 knottede1-like gene. Plant J. 11:853-861.

Shivprasad, S., Pogue, G. P., Lewandowski, D. J., Hidalgo, J., Donson, J., Grill, L. K., and Dawson, W. O. 1999. Heterologous sequences greatly affect foreign gene expression in tobacco mosaic virus-based vectors. Virology 255:312-323.

Smith, N. A., Singh, S. P., Wang, M. B., Stoutjesdijk, P. A., Green, A. G., and Waterhouse, P.M. 2000. Total silencing by intron-spliced hairpin RNAs. Nature 407:319-320.

Tamai, A., and Meshi, T. 2001. Tobamoviral movement protein transiently expressed in a single epidermal cell functions beyond multiple plasmodesmata and spreads multicellularly in an infection-coupled manner. Mol. Plant-Microbe Interact. 14:126-134.

Watanabe, Y., Meshi, T., and Okada, Y. 1984. The initiation site for transcription of the TMV 30-kDa protein messenger RNA. FEBS (Fed. Eur. Biochem. Soc.) Lett. 173:247-250.

Watanabe, Y., Meshi, T., and Okada, Y. 1987. Infection of tobacco protoplasts with in vitro transcribed tobacco mosaic virus RNA using an improved electroporation method. FEBS (Fed. Eur. Biochem. Soc.) Lett. 219:65-69.

Watanabe, T., Honda, A., Iwata, A., Ueda, S., Hibi, T., and Ishihama, A. 1999. Isolation from tobacco mosaic virus-infected tobacco of a solubilized template-specific RNA-dependent RNA polymerase containing a 126K/183K protein heterodimer. J. Virol. 73:2633-2640.

Wesley, S. V., Helliwell, C. A., Smith, N. A., Wang, M. B., Rouse, D. T., Liu, Q., Gooding, P. S., Singh, S. P., Abbott, D., Stoutjesdijk, P. A., Robinson, S. P., Gleave, A. P., Green, A. G., and Waterhouse, P. M. 2001. Construct design for efficient, effective and high-throughput gene silencing in plants. Plant J. 27:581-590.

Winter, N., Kollwig, G., Zhang, S., and Kragler, F. 2007. MPB2C, a microtubule-associated protein, regulates non-cell-autonomy of the homeodomain protein KNOTTED1. Plant Cell 19:3001-3018. 